\title{
What is the Diagnosis?
}

\section{CASE PRESENTATION}

Patient from male gender, 60 years of age, referred for ablation for symptomatic ventricular arrhythmia despite treatment with amiodarone. Patient with chronic dilated cardiomyopathy post-myocarditis with optimized therapy and functional class II. A previous electrophysiological study showed sinus rhythm with a pattern of left branch block (LBB) ( $\mathrm{QRS}=150 \mathrm{~ms}$ ), an interval of $50 \mathrm{~ms}$ and absence of ventricular tachyarrhythmia Through ventricle extra-systoles ( $20 \%$ 24h Holter), the patient was submitted to ablation. The initial entry in the electrocardiogram (ECG) and the HV interval are shown in Fig. 1. During the screening, it was noticed the finding presented in Fig. 2. How is that explainable?

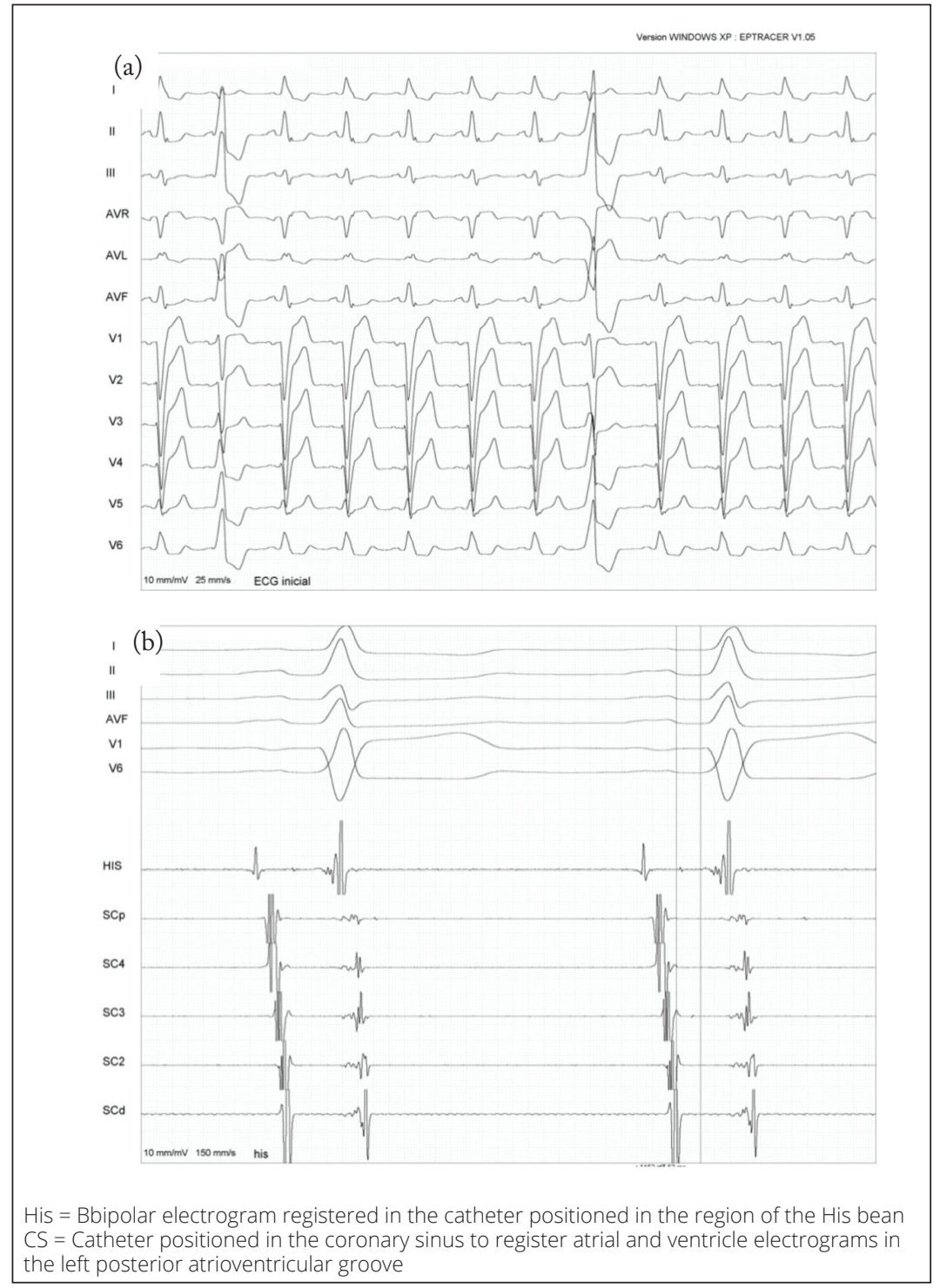

Figure 1. Electrocardiogram initial of sinus rhythm entry, LBB, and isolated ventricle extra-systoles. In the inferior image (b), it is possible to see the intracavitary entry of the His bean with HV interval of $50 \mathrm{~ms}$. 


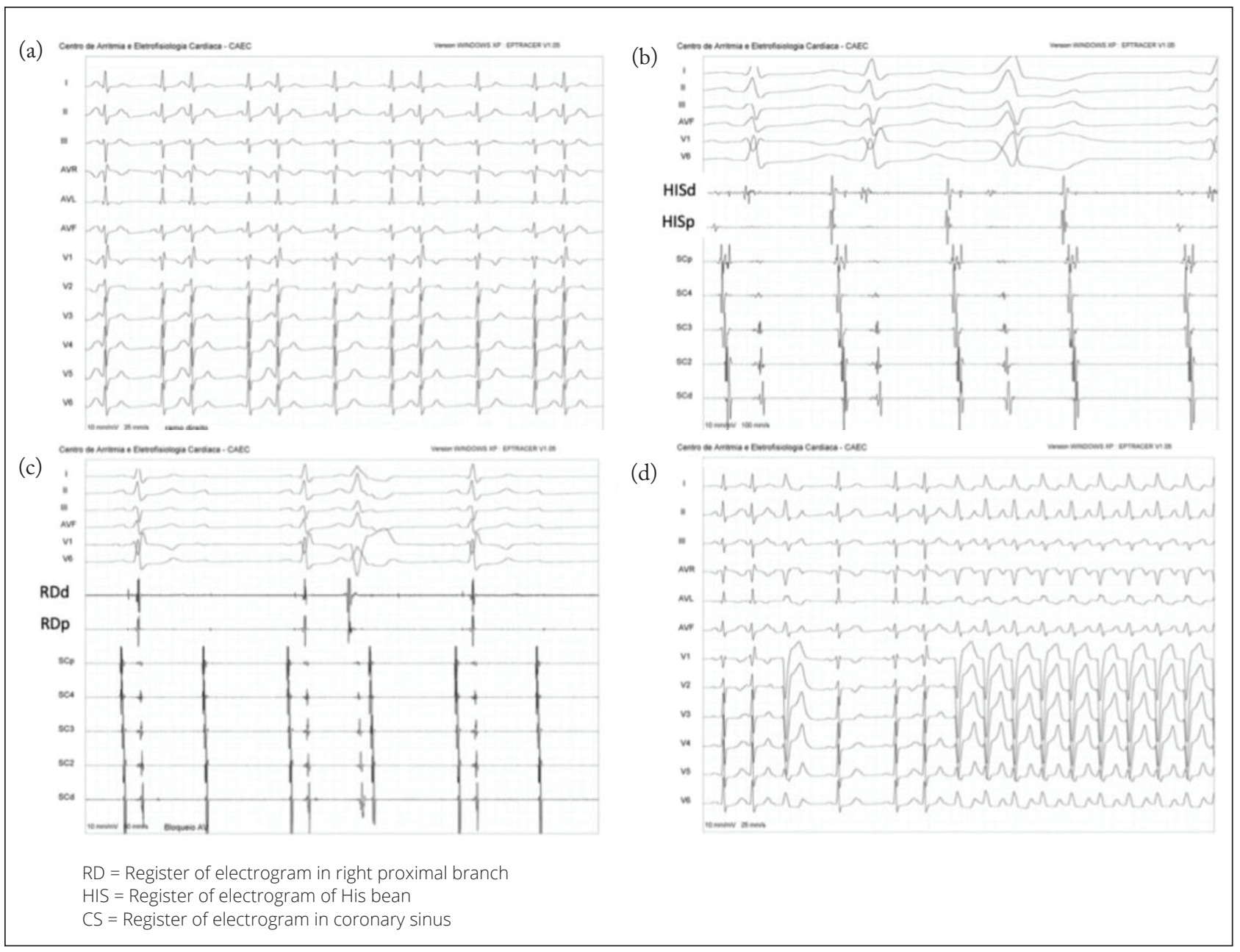

Figure 2. Second-degree atrioventricular block.

\section{ANSWER}

During sinus rhythm, there was the appearance of several degrees and blocks in the atrioventricular conduction (Fig. 2). It is essential to mention that the patient from this case already presented LBB and HV interval within normal (Fig. 1). In Figure 2a, it is possible to notice sinus rhythm with an atrioventricular block (AVB) of the second degree. Analyzing the ECG, it is noticed frequency in the atrioventricular conduction before the block (3:2 pattern), suggesting a diagnosis of second-degree AVB Wenckenbach type. Such block is expected at a nodal level. However, two points suggest that it might be not happening in the atrioventricular knot (AVN): 1) fixed PR interval; and 2) different degrees of RBB. After the analysis of the electrogram from His bean, it was verified an enhance in the HV interval before the infra-hissiane block happens, which makes the diagnosis of the Wenckenbach phenomenon in the conduction through the right branch. In Figs. $2 \mathrm{c}$ and $2 \mathrm{~d}$, it is noticed several degrees of conduction through the right branch, as already described, which is associated with slowing conduction through the previously affected left branch. Fig. $2 \mathrm{~b}$ registers 2:1 infra-hissiane second-degree AVB, with ventricle isolated extra-systole, retrogressively conducting through the right branch and AVK, as well as promoting the subsequent enhancement of the AH interval.

The following diagram presents explanations for the electrophysiological traces (Fig. 3), which lead to the following conclusions: occurrence of 1) preexistent LBB with intermittent anterograde conduction; 2) infra-hissiane second degree; 3) Wenckenbach block in the right branch, and 4) occult nodal conduction after VES. 


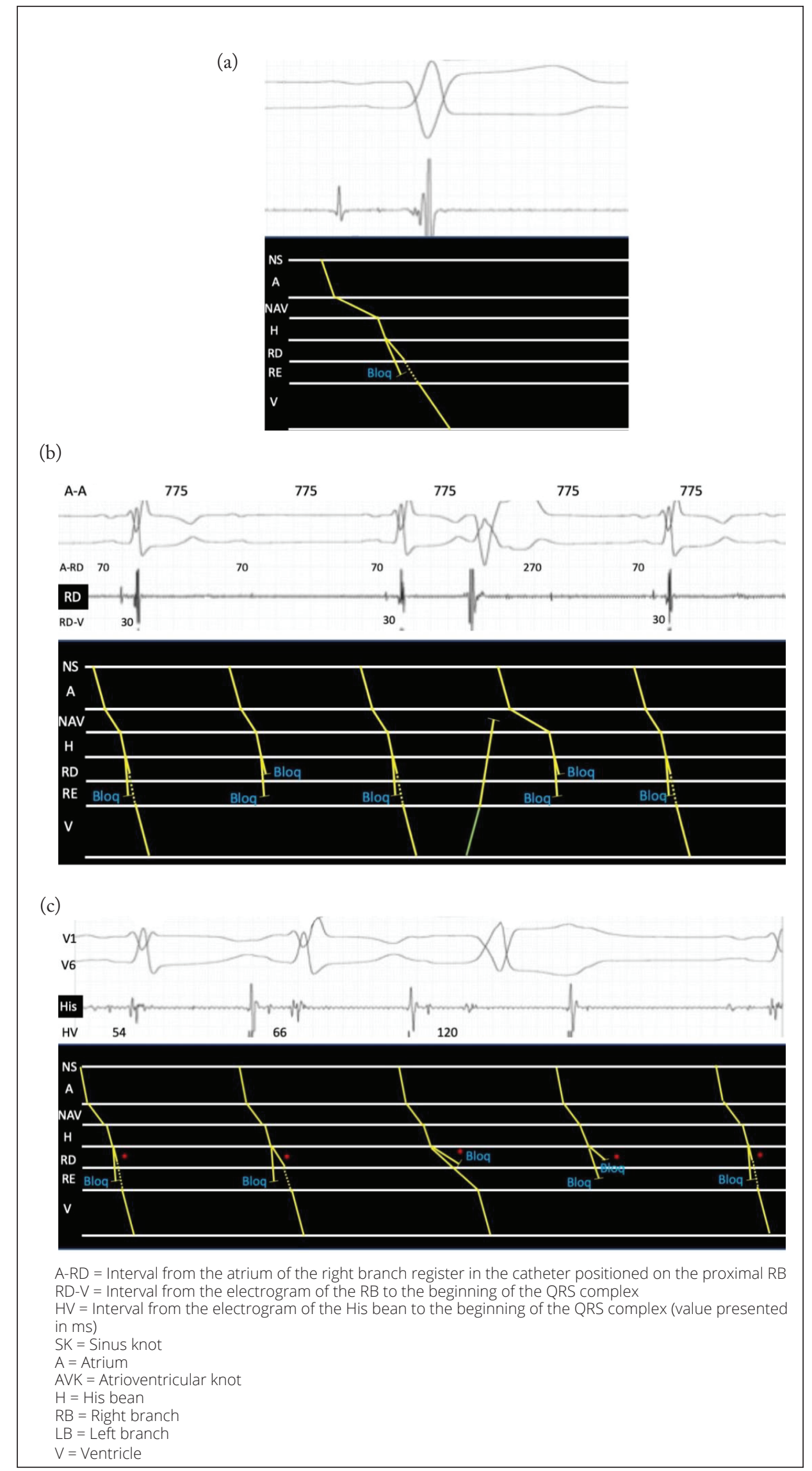

Figure 3. Diagram explaining the conduction disorders. (a) Basal atrioventricular conduction with LBB pattern. (b) 2:1 infra-hissiane second-degree AVB and nodal conduction promoted by VES, retrograde conduction to AVK. (c) Wenckebach phenomenon (in red) through RB with partial conduction through LB (LBB pattern) before the AV block. 


\section{REFERENCES}

1. Josephson ME. Josephson's clinical cardiac electrophysiology: techniques and interpretations. 5th ed. Philadelphia, PA: Wolters Kluwer; 2016.

2. Issa ZF, Miller JM, Zipes DP. Clinical arrhythmology and electrophysiology: a companion to Braunwald's heart disease. 3rd ed. Philadelphia, PA: Elsevier; 2019. https://doi.org.10.1016/B978-1-4160-5998-1.X0001-8

\section{AUTHOR}

\section{Cristiano de Oliveira Dietrich}

1. Centro de Arritmias e Eletrofisiologia Cardíaca - São Paulo/SP - Brazil.

*Correspondence author: centrodearritmias@gmail.com 